\title{
Loss of NifQ Leads to Accumulation of Porphyrins and Altered Metal-Homeostasis in Nitrogen-Fixing Symbioses
}

\author{
Maged M. Saad, ${ }^{1,2}$ Sophie Michalet, ${ }^{3}$ Romain Fossou, ${ }^{1}$ Marina Putnik-Delić, ${ }^{4}$ Michèle Crèvecoeur, ${ }^{1}$ \\ Julien Meyer, ${ }^{3}$ Chloé de Malézieux, ${ }^{1}$ Gérard Hopfgartner, ${ }^{5}$ Ivana Maksimović, ${ }^{4}$ and Xavier Perret ${ }^{1, \dagger}$ \\ ${ }^{1}$ University of Geneva, Sciences III, Department of Botany and Plant Biology, Microbiology Unit, 30 quai Ernest-Ansermet, $\mathrm{CH}-$ \\ 1211 Geneva 4, Switzerland; ${ }^{2}$ King Abdullah University of Science and Technology (KAUST), Biological and Environmental \\ Sciences and Engineering Division (BESE), Thuwal 6900-2355, Kingdom of Saudi Arabia; ${ }^{3}$ University of Geneva, Mass \\ Spectrometry Core Facility (MZ 2.0), Faculty of Sciences, Bd d'Yvoy 11, CH-1211 Geneva 4, Switzerland; ${ }^{4}$ University of Novi \\ Sad, Faculty of Agriculture, Novi Sad, Serbia; and ${ }^{5}$ University of Geneva, Department of Inorganic and Analytical Chemistry, \\ Faculty of Sciences, 26 quai Ernest-Ansermet, $\mathrm{CH}-1211$ Geneva 4, Switzerland
}

Accepted 24 July 2018.

\begin{abstract}
Symbiotic nitrogen fixation between legumes and rhizobia involves a coordinated expression of many plant and bacterial genes as well as finely tuned metabolic activities of micro- and macrosymbionts. In spite of such complex interactions, symbiotic proficiency remains a resilient process, with host plants apparently capable of compensating for some deficiencies in rhizobia. What controls nodule homeostasis is still poorly understood and probably varies between plant species. In this respect, the promiscuous Sinorhizobium (Ensifer) fredii strain NGR234 has become a model to assess the relative contribution of single gene products to many symbioses. Here, we describe how a deletion in nifQ of NGR234 (strain NGR $\Delta$ nifQ) makes nodules of Vigna unguiculata, $V$. radiata, and Macroptilium atropurpureum but not of the mimisoid tree Leucaena leucocephala, purple-red. This peculiar dark-nodule phenotype did not necessarily correlate with a decreased proficiency of NGR $\Delta$ nifQ but coincided with a 20 -fold or more accumulation of coproporphyrin III and uroporphyrin III in V. unguiculata nodules. Porphyrin accumulation was not restricted to plant cells infected with bacteroids but also extended to the nodule cortex. Nodule metal-homeostasis was altered but not sufficiently to prevent assembly and functioning of nitrogenase. Although the role of NifQ in donating molybdenum during assembly of nitrogenase cofactor FeMo-co makes it essential in free-living diazotrophs, our results highlight the dispensability of NifQ in many legume species.
\end{abstract}

In soils with limited nitrogen sources, most legume species form beneficial associations with nitrogen-fixing soil bacteria collectively called rhizobia. In legume crops such as soybean,

M. M. Saad and S. Michalet contributed equally to this work.

${ }^{\dagger}$ Corresponding author: Xavier Perret; E-mail xavier.perret@unige.ch

Funding: Financial support was provided by the University of Geneva, the Schweizerischer Nationalfonds zur Förderung der Wissenschaftlichen Forschung (Swiss National Science Foundation) (grants 31003A-146548 and 31003A-173191), and the Ministry of Education, Science and Technological Development of Serbia (TR 31016).

*The $\boldsymbol{e}$-Xtra logo stands for "electronic extra" and indicates that nine supplementary figures are published online.

(c) 2019 The American Phytopathological Society bean, or chickpea, reduction of atmospheric nitrogen $\left(\mathrm{N}_{2}\right)$ by proficient rhizobia is restricted to specialized root organs called nodules. To express and assemble the nitrogenase complex, rhizobia must first gain access to nodule cells, within which they differentiate into bacteroids capable of reducing $\mathrm{N}_{2}$ into ammonia (Downie 2014). Infected nodule cells may contain as many as thousands of bacteroids that populate the host cytoplasm in the form of symbiosomes, bacteroids surrounded by a peribacteroid membrane of plant origin. Depending on the host and nodule type, the number of bacteroids within each symbiosome may vary (Sprent et al. 2017). Within nodule cells, bacteroids encounter a cellular environment tuned to maximize nitrogenase activity. A cortical oxygen diffusion barrier that surrounds the infected nodule tissue and the synthesis of leghemoglobins ( $\mathrm{Lb})$ by infected nodule cells contribute to form the microaerobic environment that protects rhizobial nitrogenase from irreversible inactivation by traces of free oxygen (Udvardi and Poole 2013). Very abundant inside nodules, Lb support bacteroid respiration but also give to nitrogen-fixing nodules a characteristic pinkish to rosy color. RNA interference (RNAi) experiments in Lotus japonicus confirmed that decreased levels of Lb compromised symbiotic nitrogen fixation (Ott et al. 2005). Higher concentrations of free $\mathrm{O}_{2}$ inside nodules of LbRNAi lines destabilized nitrogenase, altered bacteroid and plant cell differentiation (Ott et al. 2009), and impaired the plant antioxidative machinery (Günther et al. 2007). In return for reduced forms of nitrogen, host plants provide rhizobia with nutriments such as dicarboxylic acids and amino acids that, together, sustain the intense metabolism of $\mathrm{N}_{2}$-fixing bacteroids (Poole et al. 2018)

To fix nitrogen, rhizobia use a molybdenum (Mo)-dependent nitrogenase enzyme complex. Assembly and maturation of Monitrogenase has been well documented in free-living diazotrophs such as Azotobacter vinelandii or Klebsiella pneumoniae (Rubio and Ludden 2005, 2008). Rhizobial Mo-nitrogenase can be subdivided into two iron $(\mathrm{Fe})$ proteins, each made of two NifH subunits, which frame a MoFe protein core $\left(\alpha_{2} \beta_{2^{-}}\right.$ tetramer) constituted of two NifD and two NifK proteins. Fe proteins act as electron donors to the central catalytic MoFe protein core. In addition to the structural NifH, NifD, and NifK proteins, the Mo-nitrogenase also includes a number of essential metalloclusters (Hu and Ribbe 2016). One such $\left[\mathrm{Fe}_{4} \mathrm{~S}_{4}\right]$ cluster is found at the interface of $\mathrm{NifH}$-dimers in $\mathrm{Fe}$ proteins while the MoFe-protein core carries $\left[\mathrm{Fe}_{8} \mathrm{~S}_{7}\right] \mathrm{P}$-clusters at NifDNifK interfaces and one $\left[\mathrm{MoFe}_{7} \mathrm{~S}_{9} \mathrm{C}\right.$-homocitrate] M-cluster 
embedded in each NifD. The M-cluster, also known as the FeMo-cofactor (or FeMo-co), is essential for nitrogenase activity because it represents the active site of the enzyme. Assembly of the nitrogenase metalloclusters, and of FeMo-co in particular, is a complex process that mobilizes a number of scaffold proteins such as NifE and NifN (Hu and Ribbe 2016; Jiménez-Vicente et al. 2015). It was proposed that NifE, NifN, and $\mathrm{NifH}$ together form a central node where the sequential addition of $\mathrm{Fe}, \mathrm{Mo}$, and homocitrate coalesces into a mature FeMo-co (Hernandez et al. 2009; Jiménez-Vicente et al. 2015). In free-living diazotrophs, FeMo-co assembly also requires NifQ proteins that donate Mo to NifEN/NifH complexes (Hernandez et al. 2008). Accordingly, NifQ mutants of K. pneumoniae were all defective in nitrogen fixation unless extracellular levels of molybdate were increased above the nanomolar range (Imperial et al. 1984). In rhizobia, the importance of NifQ in symbiosis is less clear and probably host dependent. A number of wellstudied strains such as Sinorhizobium (Ensifer) meliloti 1021 or Rhizobium leguminosarum bv. viciae 3841 completely lack nifQ genes (Masson-Boivin et al. 2009). In other narrow hostrange rhizobia such as Neorhizobium galegae strains HAMBI $540^{\mathrm{T}}$ and HAMBI 1141, polar mutations in nifQ sequences made derivative strains ineffective on their normal hosts Galega orientalis and G. officinalis (Österman et al. 2015). By contrast, nifQ deletion in the promiscuous $S$. fredii strain NGR234 (yielding mutant NGR $\triangle$ nifQ) reduced but did not abolish symbiotic proficiency on Leucaena leucocephala whereas it had no measurable effect on symbiosis with Vigna unguiculata (cowpea) (Fumeaux et al. 2011). Whether these differences in symbiotic requirement for NifQ in rhizobia depend upon the levels of Mo within nodules of host plants is unknown. However, host-dependent effects on nitrogen fixation were also reported for loci other than nifQ. For example, in rhizobia (e.g., Mesorhizobium loti) lacking an equivalent to the homocitrate synthase NifV of A. vinelandii (Zheng et al. 1997), host plants such as Lotus japonicus were shown to provide bacteroids with homocitrate (Hakoyama et al. 2009). For the photosynthetic Bradyrhizobium strain ORS285, requirement for nifV during symbiotic $\mathrm{N}_{2}$-fixation with Aeschynomene spp. was found to be host plant dependent (Nouwen et al. 2017). Furthermore, one ABC transport system of Bradyrhizobium japonicum (now called B. diazoefficiens) strain 110 was shown to be required for effective nitrogen fixation on Macroptilium atropurpureum (siratro) but not on soybean (Koch et al. 2010). All of these findings illustrate how tightly linked the metabolisms of bacteroids and host plants are, with transport processes to and from bacteroids ensuring proper nodule functioning during symbiosis.

Metalloproteins, whether of plant or bacteroid origins, play crucial roles in symbiosis, including conversion of nitrogen to ammonia (nitrogenase), maintenance of microaerobic conditions (e.g., Lb), or elimination of free radicals (e.g., catalases). Metal trafficking and homeostasis in root nodules are biologically relevant, and metal deficiencies in soils often lead to impaired nitrogen fixation (González-Guerrero et al. 2014, 2016). Among metalloproteins, hemoproteins are extremely diverse; support many of life's essential processes whether in microbes, plants, or animals; and often have characteristic spectroscopic properties (Reedy and Gibney 2004). For example, initially identified as respiratory pigments, cytochromes were soon classified on the basis of their lowest energy absorption band in the reduced state (Keilin 1925). Heme is a coordination complex consisting of an Fe ion coordinated to protoporphyrin IX, which itself results from the oxidation of protoporphyrinogen IX. Although plastidic and mitochondrial isoforms of protoporphyrinogen IX oxidase (EC 1.3.3.4) exist in plants, synthesis of protoporphyrinogen IX is thought to occur almost exclusively in plant plastids (Mochizuki et al.
2010). Protoporphyrin synthesis is considered to begin with 5 aminolevulinic acid that is the universal precursor of all tetrapyrroles (Supplementary Figure S1) (Brzezowski et al. 2015). Protoporphyrin IX is itself at the crossroads of two essential pathways: insertion of a magnesium $\left(\mathrm{Mg}^{2+}\right)$ ion leads to chlorophyll synthesis whereas addition of $\mathrm{Fe}^{2+}$ by ferrochelatase converts it to heme. Interestingly, abnormal heme synthesis in animals results in diseases called porphyria, in which excess of porphyrins or their precursors is eventually excreted, making urine purple-red. In plants, deficiency in tetrapyrrole synthesis can be lethal when severe but may also result in phototoxicity because of accumulated porphyrin intermediates and derivative molecules. Among these porphyrin intermediates, coproporphyrin III is a dead-end product obtained by oxidation of the main pathway intermediate coproporphyrinogen III, and uroporphyrin III results from autooxidation of uroporphyrinogen III.

Here, we report that, on $V$. unguiculata, V. radiata (mung bean), and $M$. atropurpureum, a nifQ-deleted mutant of $S$. fredii strain NGR234 (NGRAnifQ) formed nodules of a striking purplered color. In $V$. unguiculata, this peculiar phenotype coincided with a marked accumulation of coproporphyrin III and uroporphyrin III inside cortical cells of nodules, suggesting that the pathway for tetrapyrrole biosynthesis was affected. In spite of significant changes in nodule metal homeostasis, symbiotic efficacy of NGR $\triangle$ nif $Q$ bacteroids remained at wild-type levels. These results illustrate the subtle interdependence and fine tuning of plant and bacteroid metabolisms, and how resilient nitrogen-fixing associations are to homeostatic perturbations. In this context, studying the role and importance of each of the nitrogen fixation (nif or fix) genes in a promiscuous strain such as NGR234 may provide important clues as to how different plant species adapt nodule metabolism to better meet the needs of endosymbiotic bacteroids.

\section{RESULTS}

\section{Symbiotic phenotypes of NGRAnifQ on host plants.}

Contribution of NifQ to symbiotic nitrogen fixation was examined by inoculating NGR234 and NGR $\Delta$ nif $Q$ onto diverse legumes that form either determinate (e.g., V. unguiculata) or indeterminate (L. leucocephala) nodules. Initial studies showed that parent and nifQ-deleted strains had similar symbiotic proficiencies on $V$. unguiculata, whereas L. leucocephala plants inoculated with NGR $\triangle$ nif $Q$ had, on average, a shoot dry weight (SDW) reduced by approximately $30 \%$ (Fumeaux et al. 2011). Further experiments confirmed that deletion of nifQ in NGR234 also resulted in a $50 \%$ decrease in the dry weight of $M$. atropurpureum shoots at 42 days postinoculation (dpi), which correlated with a $30 \%$ reduction in nodule number (Table 1). On Cajanus cajan (pigeon pea), SDW of plants inoculated with NGR $\triangle$ nifQ was also reduced by approximately $20 \%$, whereas the total number and total fresh weight of nodules per plant remained almost unchanged. These nodulation assays indicated that importance of NifQ for symbiotic nitrogen fixation varied between plant species but did not correlate with a specific nodule type. On a number of legume hosts (V. radiata, V. unguiculata, $M$. atropurpureum, and, to a lesser extent, C. cajan); however, NGR $\Delta$ nifQ $Q$ induced nodules of a distinctively darker red to purple color when compared with pink nitrogen-fixing nodules infected by NGR234 (Fig. 1). This rather unusual phenotype, obvious on roots of $V$. unguiculata 'Red Caloona' (Fig. 1A), was even more pronounced when the nifQ-deleted strain was inoculated onto $V$. radiata 'King' (Fig. 1B to D). Microscopy observation of nodule sections showed that, whereas Lb accumulated mostly within plant cells infected with NGR234 bacteroids (Fig. 1C), the color of cortical cells of nodules formed by 
NGR $\Delta$ nifQ was purple-red (Fig. 1D). No other significant difference in nodule or bacteroid ultrastructures was observed when nodule sections were examined by electron microscopy (Supplementary Figure S2). Such a peculiar nodule color on otherwise healthy-looking plants prompted us to determine the chemical nature of molecules or pigments responsible for making NGR $\Delta$ nif $Q$ nodules purple-red.

\section{Comparing the UV-visible absorption spectra} of nodule extracts.

Once treated to remove plant debris and bacteroids, extracts of $V$. unguiculata nodules formed $42 \mathrm{dpi}$ with the parent and
nifQ-deleted strains were examined by ultrahigh-performance liquid chromatography (UHPLC). For comparison, some samples were also treated with trichloroacetic acid to precipitate proteins. Whether or not nodule extracts were depleted of proteins, all supernatants prepared from NGR $\Delta$ nifQ nodules were notably more colored than those obtained from NGR234 nodules. To facilitate subsequent analyses, all nodule extracts were then concentrated by evaporation and stored as dried materials at $-60^{\circ} \mathrm{C}$ until further use. For subsequent analyses, dried nodule extracts were resuspended at a final concentration of nodule fresh weight at approximately $70 \mu \mathrm{g} / \mu \mathrm{l}$ of $5 \%$ acetonitrile $(\mathrm{ACN})$ and $0.1 \%$ formic acid (FA) aqueous solution.

Table 1. Symbiotic proficiencies of NGR234 and NGRAnifQ on Macroptilium atropurpureum 'Siratro' and Cajanus cajan 'IRLI 1655'a

\begin{tabular}{|c|c|c|c|c|c|}
\hline Legume tested & Inoculant & Plants & $\mathbf{m N N}$ & mNFW (mg) & mSDW (mg) \\
\hline \multirow[t]{3}{*}{ M. atropurpureum (test 1) } & NGR234 & 15 & $86.6( \pm 39.7)^{*}$ & $592.5( \pm 286.9)$ & $776.2( \pm 429.3)^{*}$ \\
\hline & NGR $\Delta n i f Q$ & 15 & $59.0( \pm 21.1)^{*}$ & $419.7( \pm 216.8)$ & $352.5( \pm 186.2)^{*}$ \\
\hline & No inoculum & 8 & 0.0 & 0.0 & $30.6( \pm 5.7)$ \\
\hline \multirow[t]{3}{*}{ M. atropurpureum (test 2) } & NGR234 & 12 & $68.0( \pm 18.5)^{*}$ & $519.4( \pm 207.3)$ & $616.4( \pm 294.5)^{*}$ \\
\hline & NGR $\Delta$ nifQ & 12 & $51.8( \pm 17.8)^{*}$ & $345.5( \pm 202.8)$ & $309.2( \pm 181.3)^{*}$ \\
\hline & No inoculum & 6 & 0.0 & 0.0 & $22.2( \pm 3.5)$ \\
\hline \multirow[t]{3}{*}{ C. cajan 'IRLI 1655 (test 1) } & NGR234 & 15 & $10.2( \pm 3.6)$ & $326.5( \pm 134.6)^{*}$ & $751.9( \pm 307.5)$ \\
\hline & NGR $\Delta n i f Q$ & 14 & $10.7( \pm 4.4)$ & $194.8( \pm 63.2)^{*}$ & $577.1( \pm 230.3)$ \\
\hline & No inoculum & 12 & 0.0 & 0.0 & $123.2( \pm 40.6)$ \\
\hline \multirow[t]{3}{*}{ C. cajan 'IRLI 1655 (test 2) } & NGR234 & 13 & $8.6( \pm 3.4)$ & $220.8( \pm 83.9)$ & $620.5( \pm 211.7)$ \\
\hline & NGR $\Delta n i f Q$ & 14 & $8.4( \pm 3.2)$ & $201.7( \pm 107.0)$ & $496.2( \pm 233.2)$ \\
\hline & No inoculum & 12 & 0.0 & 0.0 & $100.3( \pm 24.5)$ \\
\hline
\end{tabular}

${ }^{a}$ Nodulation tests were performed in Magenta jars, with two plants per pot grown under controlled conditions for 42 days postinoculation. Symbiotic phenotypes of strains were reported as the mean nodule number (mNN), mean nodule fresh weight (mNFW), and mean shoot dry weight (mSDW) per plant, with standard deviations shown in parentheses. Corresponding values of NGR234 and NGR $\Delta$ nifQ found to be different at the 5\% level (Student's $t$ test) are marked with an asterisk.
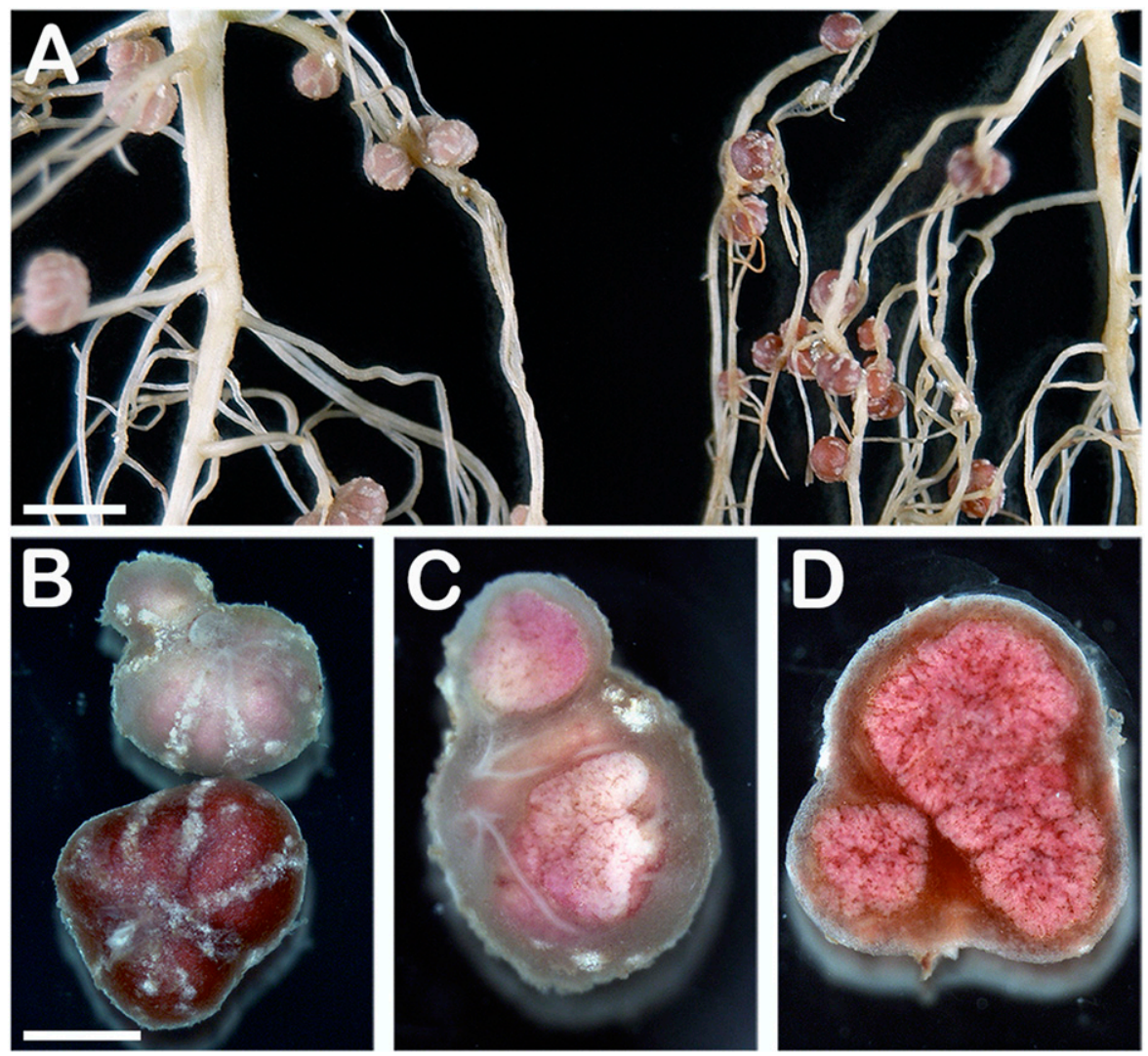

Fig. 1. NGR $\triangle$ nifQ forms dark-red nodules on various hosts, including Vigna spp. Nodules formed by NGR $\Delta$ nifQ are notably darker than those infected with NGR234.A, Root sections of Vigna unguiculata 'Red Caloona' photographed side by side 28 days postinoculation (dpi) with NGR234 (left) or NGR $\Delta$ nifQ (right); B, two 42-dpi nodules of $V$. radiata 'King' formed by NGR234 (top) or NGR $\Delta$ nifQ (bottom); sections of the same nodules infected with C, NGR234 or D, NGR $\triangle$ nifQ . Scales correspond to 5 and $1 \mathrm{~mm}$ in panels A and B, respectively. 
The ultraviolet-visible spectrum of each of the nodule extracts, with or without proteins, was then determined. Absorption spectra of protein-containing extracts prepared from NGRAnifQ nodules were characterized by peaks at 408, 496, 536, and $572 \mathrm{~nm}$ (Fig. 2A). Spectra beyond the $600-\mathrm{nm}$ range showed no major additional peak or difference. Once depleted of proteins, spectra of nodule extracts retained a single major peak at $404 \mathrm{~nm}$ that was more than sevenfold greater in NGR $\Delta$ nifQ preparations than in NGR234 nodule extracts prepared in the same way (Fig. 2B). These results indicated that protein-free nodule extracts differed remarkably in the 400-nm range.

\section{Identification of compounds}

making NGR $\Delta$ nifQ nodules a darker red.

This major difference at $400 \mathrm{~nm}$ in UV spectra of protein-free nodule extracts was further investigated using UHPLC coupled with electrospray ionization (ESI) tandem mass spectrometry (MS/MS) and diode array detection (DAD), in a mode allowing simultaneous acquisitions of UV, MS, and MS/MS spectra. Typical extracted wavelength chromatograms obtained at 400 $\mathrm{nm}$ for protein-free preparations of nodules formed $42 \mathrm{dpi}$ with NGR234 or NGR $\Delta$ nifQ are shown in Figure 3A and 3B, respectively. The most significant differences between the spectra obtained with NGR234 and NGR $\Delta$ nifQ nodule extracts were found between 7.5- and 14.0-min retention times $\left(t_{R}\right)$, with two major peaks at 9.9 and $13.8 \mathrm{~min}$. The 190- to 600-nm DAD spectra obtained for each of the 9.9- and 13.8-min chromatogram peaks showed several bands characteristic of metal-free
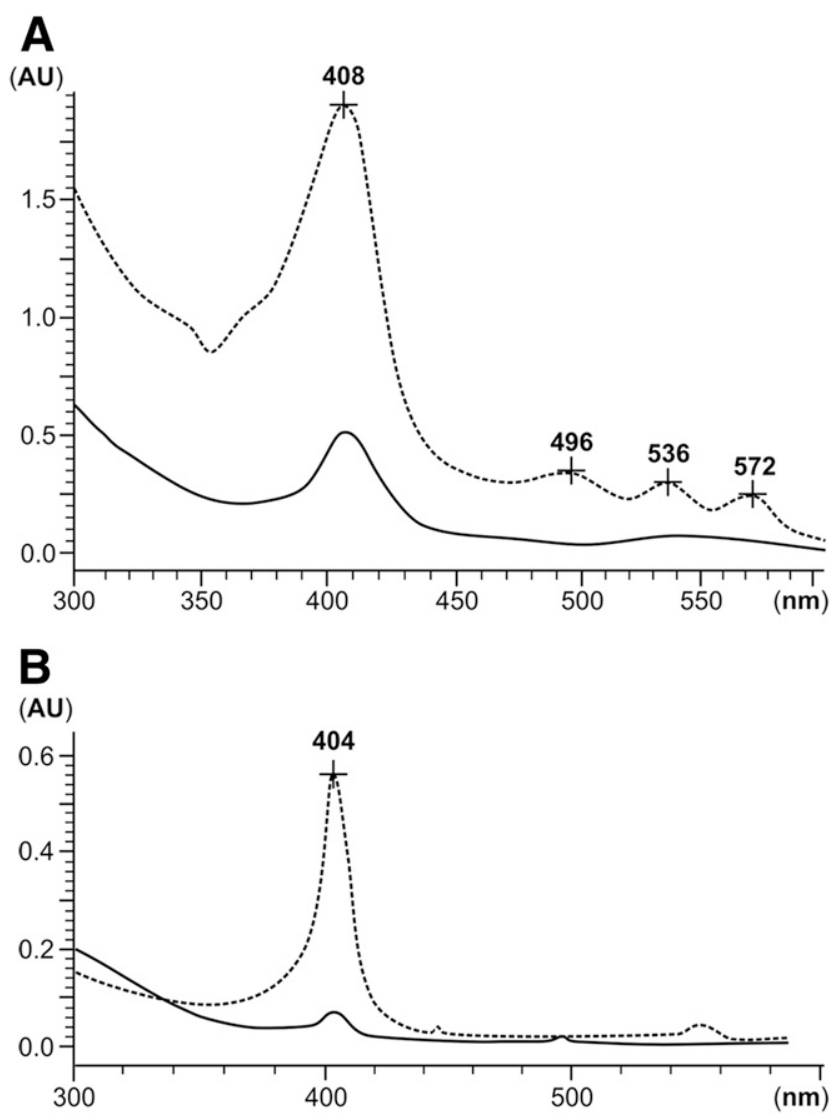

Fig. 2. UV-visible absorption spectra of extracts of nodules formed by NGR234 or NGR $\Delta$ nifQ on roots of Vigna unguiculata. A, The 300- to 600$\mathrm{nm}$ absorbance (AU) spectra obtained with crude extracts of $V$. unguiculata 'Red Caloona' root nodules formed 42 days postinoculation with NGR234 (solid line) or NGR $\Delta$ nifQ (dotted line); B, spectra obtained with similar nodule extracts after precipitation of proteins with trichloroacetic acid. Note the single peak at $404 \mathrm{~nm}$, whose composition was further analyzed. porphyrins: an intense absorption B or Soret band between 390 and $425 \mathrm{~nm}$ that varies according to macrocycle substitutions and two to four weaker Q bands between 480 and $700 \mathrm{~nm}$ (Rimington 1960). The fact that extracts of nodules enticed by NGRAnifQ contained higher concentrations of specific porphyrins was further corroborated when extracted wavelength chromatograms at $400 \mathrm{~nm}$ for commercial uroporphyrin III and coproporphyrin III standards also displayed peaks at 9.9- and 13.8-min $t_{R}$, respectively (Fig. 3C and 3D), as well as characteristic B and Q bands (Supplementary Figs. S3 and S4). Furthermore, when coinjected together with nodule extracts, the unique peak produced by uroporphyrin III and coproporphyrin III standards perfectly overlapped the major fluorescence peaks observed with NGR $\Delta$ nifQ nodule extracts at respectively, 9.9and 13.8-min $t_{R}$ (Supplementary Fig. S5).

\section{Characterization of uroporphyrin and coproporphyrin by enhanced-Q3 single MS and enhanced product ion MS/MS.}

Structures of compounds separated at 9.9- and 13.8-min $t_{R}$ were initially revealed by information-dependent acquisition (IDA) analyses, which fitted enhanced-Q3 single MS (EMS) and enhanced product ion (EPI) MS/MS data previously published for uroporphyrin and coproporphyrin (Danton and Lim 2006; Lee et al. 2012; Lim et al. 2006) as well as data obtained with commercial standards (Fig. 3). The EMS survey scan allowed detection of $26 \mathrm{~m} / \mathrm{z}$ values that are listed in Table 2, found within the 7.0- to $19.5-$ min $\mathrm{R}_{\mathrm{R}}$ and which have UV-visible

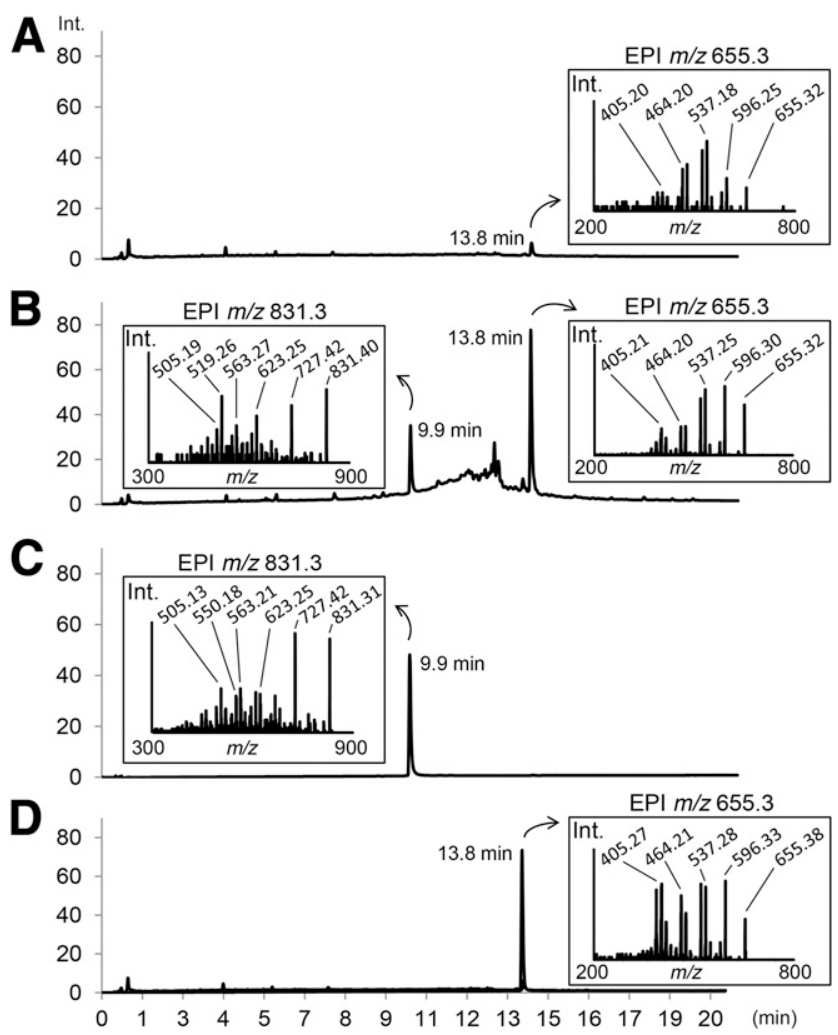

Fig. 3. Near-UV chromatograms of ultrahigh-performance liquid chromatography UV tandem mass spectrometry analyses for nodule extracts with enhanced product ion spectra shown for specific retention times of 9.9 and $13.8 \mathrm{~min}$. Near-UV chromatograms at $400 \mathrm{~nm}$ of protein-depleted extracts of Vigna unguiculata nodules formed 42 days postinoculation with parent A, NGR234 or B, NGRAnifQ mutant strains, and of commercial C, uroporphyrin III or $\mathbf{D}$, coproporphyrin III samples. Signal intensities (Int.) are reported as arbitrary units with retention times $\left(t_{R}\right)$ given in minutes. Enhanced product ion (EPI) spectra corresponding to $\mathrm{m} / \mathrm{z}$ values of 831.3 (peak at $t_{R} 9.9 \mathrm{~min}$ ) and $655.3\left(\mathrm{t}_{\mathrm{R}} 13.8 \mathrm{~min}\right.$ ) are shown in adjacent boxes. 
spectral properties comparable with those of metal-free porphyrins. The fact that specific $m / z$ values were detected at several retention times suggested the presence of chemical isomers. Except for $\mathrm{m} / \mathrm{z} 655.4$ that was characteristic of coproporphyrin and was also detected in extracts of NGR234 nodules, all other $\mathrm{m} / z$, values were specific to NGR $\Delta$ nifQ samples. Among the 26 $\mathrm{m} / \mathrm{z}$ values that were detected, analytical methods allowed us to acquire the related EPI spectra for $m / z$ 655.4, 799.4, 831.4, and 989.4. The NGR $\Delta$ nifQ EPI spectrum for $m / z 655.4$ at $t_{\mathrm{R}} 13.8 \mathrm{~min}$ (Fig. 3B) exhibited the same fragmentation pattern as the EPI spectrum for a coproporphyrin III standard at $t_{R} 13.8$ min (Fig. 3D). A similar coproporphyrin III-specific EPI profile was observed at $t_{R} 13.8 \mathrm{~min}$ (Fig. 3A), indicating that this porphyrin was also found inside nodules formed by NGR234 but at much lower concentrations. By chromatographic peak integration at $400 \mathrm{~nm}$, quantities of coproporphyrin III and uroporphyrin III were estimated at 110 and $13 \mathrm{ng} / \mathrm{mg}$, respectively, of NGR $\Delta$ nifQ nodules. By contrast, the quantity of coproporphyrin III in $V$. unguiculata nodules formed by NGR234 was estimated at $5.5 \mathrm{ng} / \mathrm{mg}$ of starting nodule material. Because no peak could be observed at $t_{R} 9.9$ min with extracts of NGR234 nodules (Fig. 3A and B), uroporphyrin III was found to accumulate specifically inside cells of nodules formed by NGRAnifQ.

\section{High-resolution MS and high-resolution MS/MS analyses of porphyrin peaks.}

Finally, accurate mass measurements were carried out with off-line high-resolution (HR)-MS and HR-MS/MS on several isolated fractions to confirm the identities of porphyrins. The major chromatogram peaks identified at $t_{R}$ of 9.9 and 13.8 min were purified by UHPLC and further analyzed by off-line quadrupole time-of-flight HR-MS to define the elementary formula of purified analytes. For $t_{R} 13.8 \mathrm{~min}$, the compound accurate mass was established at $655.2784 \mathrm{~m} / \mathrm{z}$, which yielded a single elemental composition when parameters were set as follows: selection of the first two peaks of isotopic pattern, elemental composition from $\mathrm{C}_{10} \mathrm{H}_{10} \mathrm{NO}$ to $\mathrm{C}_{50} \mathrm{H}_{200} \mathrm{~N}_{10} \mathrm{O}_{20}$, mass tolerance at $5 \mathrm{ppm}$, intensity tolerance at $5 \%$, rings plus double bonds equivalent between -0.5 and 25 , and considering only even electron states. With an elemental composition of $\mathrm{C}_{36} \mathrm{H}_{38} \mathrm{~N}_{4} \mathrm{O}_{8}$, coproporphyrin III was the only hit detected as proton adduct $\left(\left[\mathrm{M}+\mathrm{H}^{+}\right]\right)$and with $3.3 \mathrm{ppm}$ accuracy (Supplementary Fig. S6). For the $t_{\mathrm{R}}$ 9.9-min peak, accurate mass was set at $831.2385 \mathrm{~m} / \mathrm{z}$, also with a single elemental composition possible when using the same set of parameters as described above. Uroporphyrin III of elemental composition $\mathrm{C}_{40} \mathrm{H}_{38} \mathrm{~N}_{4} \mathrm{O}_{16}$ was the only hit detected as proton adduct and with 3.5-ppm accuracy (Supplementary Fig. S7). Likewise, what was obtained with EPI spectra, and HR-MS/MS spectra of $m / z 655.3$ and 831.2, perfectly matched those of coproporphyrin III and uroporphyrin III standards, respectively.

\section{Comparing metal contents of nodules formed by NGR234 and NGR $\Delta$ nifQ.}

Pyrrole macrocycle rings often frame a metal atom; therefore, we assessed whether changes in porphyrin composition coincided with modifications in the content of biologically relevant metals or essential elements such as phosphorus (P). To do so, nodules formed by NGR234 or NGRAnifQ on $V$. unguiculata, $V$. radiata, and $M$. atropurpureum were harvested at $42 \mathrm{dpi}$, dried, and finely ground. For V. radiata nodules, the total content in calcium $(\mathrm{Ca})$, cobalt $(\mathrm{Co})$, copper $(\mathrm{Cu})$, $\mathrm{Fe}, \mathrm{Mg}$, manganese $(\mathrm{Mn}), \mathrm{Mo}$, potassium $(\mathrm{K})$, and zinc $(\mathrm{Zn})$ was determined by atomic absorption spectrophotometry (for $\mathrm{Co}, \mathrm{Cu}, \mathrm{Fe}, \mathrm{Mg}, \mathrm{Mn}$, and $\mathrm{Zn}$ ) or flame photometry (Ca and $\mathrm{K}$ ). In addition, the essential element $P$ was quantified using vanadatemolybdate as reagent for spectrophotometric determination. Nodules of $V$. unguiculata and $M$. atropurpureum were only examined for the subset of $\mathrm{Fe}, \mathrm{Mo}, \mathrm{Mg}$, and $\mathrm{Zn}$ elements. Nodules formed by NGR $\Delta$ nifQ on $V$. radiata differed from those infected with NGR234 by noticeably lower metal contents, except for $\mathrm{Zn}$, whose content increased (Table 3). For the five

Table 2. List of $m / z$ values detected by enhanced-Q3 single mass spectrometry (MS) survey scan and found in the NGR $\Delta$ nif $Q$ nodule extracts, between 7.0- to 19.5 -min retention times $\left(t_{R}\right)^{a}$

\begin{tabular}{|c|c|c|c|c|}
\hline Number & $m / z$ values & MW (Da) & $\mathbf{t}_{\mathbf{R}}(\mathbf{m i n})$ & Proposed molecular assignment \\
\hline 1 & $310.9 *$ & 617.8 & 13.79 & $\ldots$ \\
\hline 2 & $328.8 *$ & 653.6 & 13.79 & $\ldots$ \\
\hline 3 & 376.5 & 375.5 & 16.89 & $\ldots$ \\
\hline 4 & 404.2 & 403.2 & 16.18 & $\ldots$ \\
\hline 5 & 529.3 & 528.3 & 12.30 & $\ldots$ \\
\hline 6 & 583.3 & 582.3 & 16.42 & $\ldots$ \\
\hline 7 & 609.3 & 608.3 & $12.06 ; 12.26$ & $\ldots$ \\
\hline 8 & 625.3 & 624.3 & 17.47 & $\ldots$ \\
\hline 9 & 627.5 & 626.5 & 13.95 & $\ldots$ \\
\hline 10 & 637.3 & 636.3 & 12.37 & MW of coproporphyrin +18 \\
\hline 11 & 655.4 & 654.4 & $11.70 ; 12.51 ; 13.60 ; 13.83 ; 15.38$ & Coproporphyrin I**; coproporphyrin III** \\
\hline 12 & 671.3 & 670.3 & 12.77 & $\ldots$ \\
\hline 13 & 677.3 & 676.3 & 13.83 & $\ldots$ \\
\hline 14 & 699.3 & 698.3 & $12.65 ; 13.83$ & 5-Carboxyl porphyrin (Bu et al. 2003) \\
\hline 15 & 715.3 & 714.3 & 13.83 & $\ldots$ \\
\hline 16 & 743.4 & 742.4 & $9.18 ; 12.07$ & 6-Carboxyl porphyrin (Bu et al. 2003) \\
\hline 17 & 784.4 & 783.4 & 12.26 & $\ldots$ \\
\hline 18 & 787.4 & 786.4 & 10.89 & 7-Carboxyl porphyrin (Bu et al. 2003) \\
\hline 19 & 799.4 & 798.4 & 12.77 & MW of coproporphyrin +144 \\
\hline 20 & 817.4 & 816.4 & 12.48 & MW of coproporphyrin $+144+18$ \\
\hline 21 & 829.5 & 828.5 & 7.58 & 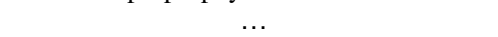 \\
\hline 22 & 831.4 & 830.4 & 10.06 & Uroporphyrin III** \\
\hline 23 & 943.3 & 942.3 & 11.94 & MW of coproporphyrin $+144+144$ \\
\hline 24 & 989.4 & 988.4 & 12.77 & MW of coproporphyrin $+144+190$ \\
\hline 25 & $1,133.2$ & $1,132.2$ & $11.99 ; 12.60$ & MW of coproporphyrin $+144+144+190$ \\
\hline 26 & $1,151.2$ & $1,151.2$ & 11.87 & MW of coproporphyrin $+144+144+190+18$ \\
\hline
\end{tabular}

${ }^{\text {a }}$ List of $m / z$ values attributed to metal-free porphyrins based upon UV-visible spectral properties. Except for two doubly charged ions marked with an asterisk $(*)$, all $\mathrm{m} / \mathrm{z}$ species were detected as singly charged ions. Double asterisks (**) indicate a single peak obtained when coinjecting sample with corresponding commercial standard. Coproporphyrin I was identified by its $t_{R}$, UV, MS, and tandem MS spectra. MW = molecular weight. 
most abundant elements ( $\mathrm{Ca}, \mathrm{Fe}, \mathrm{K}, \mathrm{Mg}$, and $\mathrm{P}$ ), variations in metal contents ranged from -3 to $-18 \%$, while nodules formed by NGR234 contained $>30 \%$ more Co. Unlike nodules of $V$. unguiculata and $V$. radiata that appeared to follow similar trends in terms of metal contents, nodules of $M$. atropurpureum enticed by NGR $\Delta$ nifQ contained more Mo than those formed by the parent strain. Thus, the lower symbiotic efficacy of the nifQmutant strain observed on $M$. atropurpureum most probably did not result from a shortage of Mo during assembly of nitrogenase. Conversely, the $28 \%$ decrease measured in Mo content inside nodules of $V$. unguiculata formed by NGR $\Delta$ nifQ did not translate into a significant reduction in symbiotic activity, because both the nifQ-deleted mutant and parent NGR234 strains had similar phenotypes on this legume host (Fumeaux et al. 2011).

\section{Genetic complementation of NGR $\Delta$ nifQ}

but not increased Mo levels restored a normal nodule color.

To confirm that loss of NifQ was responsible for the unusual nodule color, the NGR $\Delta$ nifQ mutant was complemented with a pRG960-derivative plasmid carrying nifQ downstream of its native promoter (construct pCRGnifQ). Following mobilization into NGR $\Delta$ nifQ and parent NGR234 strains, the resulting pCRGnifQ transconjugants were inoculated onto $V$. radiata plants and root systems were examined at 21 and $35 \mathrm{dpi}$. When compared with those infected with NGR $\Delta$ nifQ that carried dark-red nodules, roots of plants challenged with the complemented NGRAnifQ::pCRGnifQ or parent NGR234 strains were indistinguishable and carried normal pinkish nodules (Supplementary Fig. S8). $\beta$-Glucuronidase (GUS) staining of whole root systems confirmed that bacteroids inside nodules enticed by NGR $\triangle$ nif $Q:$ :pCRGnifQ still carried pCRGnifQ, because the native promoter upstream of nifQ also drove expression of the uidA reporter gene. Polymerase chain reactions (PCR) carried out on nodule isolates further confirmed the strain identities and presence of pCRGnifQ. Together, these results confirmed that loss of NifQ was sufficient and responsible for the purple-red phenotype of nodules formed by NGR $\Delta$ nifQ. To verify whether elevated Mo levels could suppress the nodule color phenotype, $V$. radiata was grown in the presence of increased concentrations of Mo. Roots of plants inoculated with NGR $\Delta$ nifQ and grown in the presence of the nitrogen-free plantgrowth B\&D solution (Brougton and Dilworth 1971) containing 10, 40, or 100 times higher Mo levels still carried purple-red nodules (Supplementary Fig. S9).

\section{DISCUSSION}

Color of nodules has often been a useful criterion to estimate symbiotic proficiency in rhizobia-legume interactions. Pinkish nodules, inside which abundant Lb actively control levels of free oxygen, are usually considered to be nitrogen fixing, even in the absence of additional tests to measure acetylene reduction. Conversely, nodules devoid of Lb or greenish senescent nodules are generally deemed to be nonfixing. In addition to levels of $\mathrm{Lb}$ that give their characteristic color to effective nodules, a number of publications documented the presence of unusual red pigments when plants were challenged with specific rhizobia strains. For example, unusually dark-colored nodules were reported for several tropical legumes, including Dolichos lablab (also known as Lablab purpureus) (Cloonan 1963), V. marina (Allen and Allen 1936), V. sinensis (Stamford and Neptune 1978), and V. unguiculata (Eaglesham et al. 1982; Uddin et al. 1984), but also for a temperate species such as Lupinus arboreus (Caradus and Silvester 1979). These non-Lb red pigments were reported to accumulate in the nodule cortex (Caradus and Silvester 1979) or extend from bacteroid-infected to nodule cortical zones (Eaglesham et al. 1982). The chemical nature of such red to purple-red pigments has remained elusive thus far, although the unusual water-soluble pigment of $L$. arboreus nodules was reported to share characteristics of anthocyanins with a maximum absorption in the 500-nm range (Caradus and Silvester 1979). Although no dark pigmentation was observed during subculturing of dark-nodule-forming rhizobia, strains found to synthesize melanin-like pigments enticed normal-looking pink nodules (Eaglesham et al. 1982). These observations suggested that melanin-like pigments of rhizobia were not responsible for the unusually intense pigmentation of certain nodules.

Here, we showed that the purple-red nodule phenotype provoked by NGR $\triangle$ nifQ on $V$. unguiculata and $V$. radiata (but not on Leucaena leucocephala) coincided with a marked accumulation in coproporphyrin III, uroporphyrin III, and other related porphyrins with similar UV spectra and ESI-MS/MS fragmentation patterns. Because a NifA-regulated copy of nifQ was sufficient to restore formation of pink nodules by an NGR $\Delta$ nifQ::pCRGnifQ transconjugant, absence of NifQ was sufficient to make $\mathrm{N}_{2}$-fixing nodules purple-red. NifQ-lacking rhizobia such as $S$. meliloti were never reported to provoke porphyrin accumulation in nodules, whereas $V$. radiata nodules

Table 3. Comparing the metal and phosphorous $(\mathrm{P})$ contents of nodules formed by NGR 234 and NGR $\Delta$ nifQ on roots of three legume species

\begin{tabular}{|c|c|c|c|c|c|c|c|c|c|}
\hline \multirow[b]{3}{*}{ Element } & \multicolumn{9}{|c|}{ Element contents (in ppm) in 42-dpi nodules of ${ }^{\text {a }}$} \\
\hline & \multicolumn{3}{|c|}{ Vigna radiata } & \multicolumn{3}{|c|}{ V. unguiculata } & \multicolumn{3}{|c|}{ Macroptilium atropurpureum } \\
\hline & NGR & $\Delta$ nifQ & $\operatorname{Var}(\%)$ & NGR & $\Delta n i f Q$ & $\operatorname{Var}(\%)$ & NGR & $\Delta n i f Q$ & $\operatorname{Var}(\%)$ \\
\hline $\mathrm{Ca}$ & $5,100( \pm 170.5)$ & $4,800( \pm 299.7)$ & -5.9 & NM & NM & NM & NM & NM & NM \\
\hline $\mathrm{Co}$ & $0.3( \pm 0.01)$ & $0.2( \pm 0.06)^{*}$ & -33.3 & NM & NM & NM & NM & NM & NM \\
\hline $\mathrm{Cu}$ & $11.9( \pm 0.6)$ & $10.5( \pm 0.4)$ & -11.8 & NM & NM & NM & NM & NM & NM \\
\hline $\mathrm{Fe}$ & $396.2( \pm 9.9)$ & $384.7( \pm 11.3)$ & -2.9 & $311.6( \pm 4.3)$ & $254.4( \pm 7.1)^{*}$ & -18.4 & $329.1( \pm 3.3)$ & $312.5( \pm 0.2)^{*}$ & -5.0 \\
\hline K & $5,600( \pm 173.2)$ & $5,000( \pm 208.2)$ & -10.7 & NM & NM & NM & NM & $\mathrm{NM}$ & NM \\
\hline $\mathrm{Mg}$ & $8,800( \pm 226.2)$ & $8,300( \pm 244.6)$ & -5.7 & $9,900( \pm 316.2)$ & $8,500( \pm 81.3)^{*}$ & -14.1 & $6,700( \pm 51.0)$ & $6,800( \pm 53.8)$ & +1.5 \\
\hline $\mathrm{Mn}$ & $5.7( \pm 0.05)$ & $5.2( \pm 0.02)^{*}$ & -8.8 & NM & NM & NM & NM & NM & NM \\
\hline Mo & $8.1( \pm 0.3)$ & $6.5( \pm 0.3)^{*}$ & -19.8 & $6.7( \pm 3.7)$ & $4.8( \pm 3.0)$ & -28.4 & $7.7( \pm 0.7)$ & $8.1( \pm 0.9)$ & +5.2 \\
\hline $\mathrm{P}$ & $5,100( \pm 328.8)$ & $4,400( \pm 228.3)$ & -13.7 & NM & NM & NM & NM & NM & NM \\
\hline $\mathrm{Zn}$ & $35.9( \pm 1.4)$ & $41.7( \pm 2.2)$ & +16.2 & $19.9( \pm 0.7)$ & $21.8( \pm 2.0)$ & +9.6 & $25.9( \pm 0.01)$ & $31.7( \pm 2.7)^{*}$ & +22.4 \\
\hline
\end{tabular}

${ }^{a}$ Metal contents and phosphorous were measured for dried nodules of $M$. atropurpureum, V. radiata, and V. unguiculata 42 days postinoculation (dpi) with NGR234 or NGR $\Delta$ nifQ. Measurements were more exhaustive for $V$. radiata nodules because those formed by NGR $\Delta$ nifQ displayed a pronounced purple-red phenotype. V. unguiculata and $M$. atropurpureum nodules were only examined for iron (Fe), magnesium (Mg), molybdenum (Mo), and zinc (Zn) contents. To facilitate reading of data, values for potassium $(\mathrm{K}), \mathrm{P}$, calcium $(\mathrm{Ca})$, and $\mathrm{Mg}$ that were measured as percentage of total nodule mass were converted into parts per million (ppm). $\mathrm{Cu}=$ copper and $\mathrm{NM}=$ not measured. $\mathrm{NGR}=\mathrm{NGR} 234, \Delta$ nif $Q=\mathrm{NGR} \Delta$ nif $Q$, and Var $=$ variation in element contents inside nodules Standard deviations are shown in parentheses, and asterisks mark pairs of values for NGR234 and NGR $\Delta$ nif $Q$ that are statistically different (Student's $t$ test, $\alpha=5 \%)$. 
formed by the nifQ-carrying Bradyrhizobium genosp. SA-4 strain CB756 accumulated purple-red pigments (Maskall et al. 1972). Taken together, these observations indicate that accumulation of porphyrins is not a general legume-response to the absence of NifQ in symbiotic strains but, rather, a characteristic of specific legume-rhizobia combinations. Tetrapyrroles are essential to many plant processes, including photosynthesis, detoxification of reactive oxygen species, and plastid signaling, as well as programmed cell death (Larkin 2016). Thus, biosynthesis and accumulation of tetrapyrrole intermediates is strictly controlled in plants (Brzezowski et al. 2015) as well as in bacteria (Dailey et al. 2017; Zappa et al. 2010). What mechanisms led to accumulation of coproporphyrin III and uroporphyrin III inside NGR $\Delta$ nifQ nodules is not known thus far but could result from an increase in tetrapyrrole synthesis or from an upregulated conversion of the main pathway intermediates coproporphyrinogen III and uroporphyrinogen III. Because porphyrins chelate metal ions such as Fe or Mg to achieve metabolic activities, we compared levels of various metals in nodules formed by the parent NGR234 and nifQ-derivative mutant. Indeed, metal homeostasis was altered in NGR $\Delta$ nifQ nodules but symbiotic nitrogen fixation persisted, albeit at lower levels on several hosts; for example, $M$. atropurpureum (this work) and L. leucocephala (Fumeaux et al. 2011). Thus, contribution of NifQ to NGR234 symbioses was host specific, with overall nodule levels in $\mathrm{Mo}, \mathrm{Fe}$, and $\mathrm{Mg}$ apparently sufficient to ensure a proper assembly and functioning of nitrogenase, even in the absence of NifQ. Furthermore, because NGR $\Delta$ nifQ still induced formation of dark-red nodules on roots of $V$. radiata grown in the presence of Mo at as much as $2.5 \mathrm{ppm}$ (100 times more Mo than in B\&D), abnormal accumulation of porphyrins inside nodules appeared independent of Mo concentrations in the plant environment.

Truly enough, and except for a proposed role as a reliable marker in competition studies, "the dark-nodule phenotype... has been regarded merely as an oddity, and its utility has received little attention" (Eaglesham et al. 1982). Nevertheless, deletion in NGR234 of a nonessential symbiotic protein such as NifQ triggered a marked accumulation of dead-end porphyrin products in nodules of several legume species, further illustrating the tight link and complex homeostasis of host and rhizobia metabolisms. Although the reduced proficiency of NGR $\Delta$ nifQ on some hosts confirmed that microbial prerequisites for securing nitrogen fixation differ between legume species, symbiosis remained, overall, a surprisingly robust process.

\section{MATERIALS AND METHODS}

Bacterial strains, plasmids, and growth conditions.

The parent $S$. fredii strain NGR234 (resistant to rifampicin $\left.\left[\mathrm{Rif}^{\mathrm{R}}\right]\right)$ (Stanley et al. 1988) and a nifQ-deleted derivative strain NGR $\Delta$ nifQ $\left(\mathrm{Rif}^{\mathrm{R}}\right.$ and resistant to spectinomycin $\left[\mathrm{Sp}^{\mathrm{R}}\right]$ ) (Fumeaux et al. 2011) were grown at $27^{\circ} \mathrm{C}$ on Rhizobium minimal medium supplemented with succinate (RMS) (Broughton et al. 1986) using rifampicin or spectinomycin at final concentrations of $50 \mu \mathrm{g} \mathrm{ml}^{-1}$. For constructing pCRGnifQ, the PstIBamHI insert of plasmid pXrpsL426 (Fumeaux et al. 2011) was replaced with an amplicon covering positions 148,066 to 149,430 of pNGR234a (accession number NC_000914.2) (Freiberg et al. 1997) that included the entire $693 \mathrm{bp} n i f Q$. The insert cloned in pCRGnif $Q$ also included the native nif $Q$ promoter that was oriented to drive expression of the promoter-less uidA gene of pRG960 found downstream of the BamHI cloning site (Van den Eede et al. 1992). Because pRG960 also conferred resistance to spectinomycin, transconjugants of the $\mathrm{Sp}^{\mathrm{R}}$ mutant NGR $\Delta$ nifQ harboring pCRGnifQ (NGR $\Delta$ nifQ::pCRGnifQ) were selected onto RMS supplemented with spectinomycin at $200 \mu \mathrm{g} \mathrm{ml}{ }^{-1}$.
By contrast, transconjugants of NGR234 carrying pCRGnifQ (NGR234::pCRGnifQ) were plated onto RMS supplemented with spectinomycin at $50 \mu \mathrm{g} \mathrm{ml} \mathrm{m}^{-1}$. Once transferred into recipient bacteria, correct mobilization of pCRGnif $Q$ was verified by PCR.

\section{Plant assays and GUS staining.}

Seed of C. cajan 'IRLI 16555', M. atropurpureum 'Siratro', $V$. unguiculata 'Red Caloona', and V. radiata 'King' were surface sterilized and incubated on agar plates to germinate in the dark at $27^{\circ} \mathrm{C}$. Germinated seedlings were planted in Magenta jars (two plants per pot) containing vermiculite (Lewin et al. 1990) and nitrogen-free B\&D solution (Broughton and Dilworth 1971). After a few days of incubation, each plantlet was inoculated with a $200-\mu$ l solution of $2 \times 10^{8}$ bacteria. Plants were harvested after 3,5 , or 6 weeks of growth in a controlled plant chamber with a day temperature of $27^{\circ} \mathrm{C}$, night temperature of $20^{\circ} \mathrm{C}$, and light phase of $12 \mathrm{~h}$. Shoots of each plant were dried for 2 days at $60^{\circ} \mathrm{C}$ prior to being weighed. Once harvested, root systems were cleared of vermiculite and all nodules were collected, weighed when fresh, then stored at $-60^{\circ} \mathrm{C}$ until further use. For growing plants in the presence of increased concentrations of Mo, sodium molybdate was added to B\&D solution to reach $10 \times, 40 \times(1 \mathrm{ppm})$, and $100 \times(2.5 \mathrm{ppm})$ final concentrations. For GUS staining, whole roots carrying nodules formed by NGR $\Delta$ nifQ, NGR $\Delta$ nifQ::pCRGnifQ, or NGR234:: pCRGnif $Q$ were vacuum infiltrated (twice for 15 min each) and incubated at $37^{\circ} \mathrm{C}$ inside a solution of X-GlcA buffer that consists in $0.1 \%$ sarcosyl, $0.1 \%$ triton X100, $5 \mathrm{mM} \mathrm{K}$-ferricyanide, $5 \mathrm{mM}$ K-ferrocyanide, $1 \mathrm{mM}$ EDTA, and 5-bromo-4-chloro-3-indoxyl$\beta$-glucuronic acid at $0.2 \mathrm{mg} / \mathrm{ml}$ of cyclohexyl-ammonium salt (Biosynth AG, Gstaad, Switzerland). Once colored, root systems were washed and examined for GUS activity.

\section{Transmission electron microscopy.}

For electron microscopy, harvested nodules were sectioned into two equal parts along their midaxis. Nodule sections were fixed overnight at $4{ }^{\circ} \mathrm{C}$ with $2.5 \%$ (vol/vol) glutaraldehyde in $0.1 \mathrm{M}$ Na-cacodylate buffer. Samples were washed four times for $15 \mathrm{~min}$ in Na-cacodylate buffer and postfixed in $1 \%$ (wt/vol) $\mathrm{OsO}_{4}$ in Na-cacodylate buffer for $2 \mathrm{~h}$ at $4^{\circ} \mathrm{C}$. Once rinsed in Na-cacodylate buffer, nodule samples were dehydrated in an ethanol series and embedded in Epon 812 (Fluka, Buchs, Switzerland). Initial observations were carried out by light microscopy on 1- $\mu \mathrm{m}$ sections stained with methylene blue and basic fuchsin using a microscope Nikon eclipse 80i. Then, ultrathin (80-nm) sections were obtained and stained with $2 \%$ (wt/vol) aqueous uranyl acetate and Reynold's lead citrate and observed at $120 \mathrm{kV}$ under a FEI TECNAI G2 Sphera transmission electron microscope (FEI Company, Hillsboro, OR, U.S.A.).

\section{Preparing nodule extracts for liquid chromatography.}

For each sample, at least $1 \mathrm{~g}$ of frozen nodules collected 42 dpi with NGR234 or NGR $\Delta$ nifQ was extensively ground and homogenized in $15 \mathrm{ml}$ of $15 \mathrm{mM}$ Tris- $\mathrm{HCl}(\mathrm{pH} \mathrm{7.4)}$. The resulting nodule homogenate was filtered through four layers of Miracloth (Calbiochem, La Jolla, California, U.S.A.) and the cleared filtrate centrifuged at $8,000 \times g$ for $20 \mathrm{~min}$ at room temperature to remove most plant debris and bacteroids. To precipitate proteins, $100 \%$ (wt/vol) 2,2,2-trichloroacetic acid (Sigma-Aldrich, Steinheim, Germany) was added to nodule supernatant and the mixed solution was incubated at $4^{\circ} \mathrm{C}$ for $16 \mathrm{~h}$. Precipitated proteins were separated from soluble fractions by centrifugation at $17,000 \times g$ for $12 \mathrm{~min}$. Protein-free supernatants were evaporated and concentrated using one Eppendorf 5301 concentrator centrifugal evaporator (Eppendorf $\mathrm{GmbH}$, Wesseling-Berzdor, Germany) and stored at $-60^{\circ} \mathrm{C}$ 
until further use. For chemical analyses, nodule extracts were resuspended in 5\% (vol/vol) ACN (Bisolve Chimie, Dieuze, France) and $0.1 \%$ (vol/vol) FA (Sigma-Aldrich) to a final concentration of dried nodule materials of $68 \mu \mathrm{g} / \mu \mathrm{l}$.

\section{UHPLC-DAD-ESI-MS/MS analyses.}

Liquid chromatography (LC)-MS/MS analyses were carried out on a 1290 infinity binary system equipped with a DAD (Agilent Technologies, Basel, Switzerland), coupled to a hybrid triple quadrupole-linear ion $\operatorname{trap}\left(\mathrm{Q}_{\mathrm{q}} \mathrm{Q}_{\mathrm{LIT}}\right) 3200$ QTRAP mass spectrometer that was equipped with an ESI source (Sciex, Concord, ON, Canada). During a complete LC run, the mass spectrometer was operated in IDA mode with EMS as survey scan and EPI mode as dependent scan. This acquisition mode specific to a $\mathrm{Q}_{\mathrm{q}} \mathrm{Q}_{\mathrm{LIT}}$ mass spectrometer provided MS (EMS) and MS/MS (EPI) data simultaneously. In addition, the DAD was placed in line with the mass spectrometer, allowing for UV, MS, and MS/MS spectra to be collected for each of the analytes that were separated. Systems were controlled with the Analyst software (ver. 1.6.1) and data were processed with PeakView (ver. 1.2; Sciex). Analytes were separated on a narrow bore Kinetex-C18 $2.6 \mu \mathrm{m}$ column of 150 by $2.1 \mathrm{~mm}$ (Phenomenex, Torrance, CA, U.S.A.) at $50^{\circ} \mathrm{C}$ with a constant flow rate of acidified water at $0.7 \mathrm{ml} / \mathrm{min}$ and an ACN gradient as mobile phase $(0.1 \%$ [vol/ $/ \mathrm{vol}] \mathrm{FA}$ in water and $0.1 \%$ [vol/vol] $\mathrm{ACN}$, referred to as $\mathrm{A}$ and $\mathrm{B}$, respectively). Gradient ranged from 5 to $60 \%$ in $20 \mathrm{~min}$. The autosampler was kept at $4^{\circ} \mathrm{C}$. The DAD was monitored for a range from 190 to $600 \mathrm{~nm}$. The TurboIonSpray interface was operated in positive ionization mode, and the following instrument settings were applied: nitrogen as curtain and nebulizer gas; curtain gas at $30 \mathrm{psi}, \mathrm{GS} 1$ at $50 \mathrm{psi}$, and GS2 at $60 \mathrm{psi}$; capillary voltage $=5.5 \mathrm{kV}$; declustering potential $=60 \mathrm{~V}$; and temperature $=650^{\circ} \mathrm{C}$. Survey scan was carried out with an enhanced single Q3 single MS (EMS) over a mass range of $\mathrm{m} / \mathrm{z}, 300$ to 1,500 with a dwell time of $0.030 \mathrm{~ms}$ and step size of 0.120 atomic mass unit (u). The EPI-dependent scan was performed over a mass range of $\mathrm{m} / \mathrm{z}, 100$ to 1,000 at a rate of 4,000 unified atomic mass units per second by the linear ion trap with a dynamic fill time. The duty cycle of the method was $2.75 \mathrm{~s}$. Collision energy was set at $90 \mathrm{eV}$, with a collision energy spread of $20 \mathrm{eV}$. The Q1 and Q3 resolutions were placed to give $0.7 \mathrm{u}$ at full width at half maximum for both precursor and product ions. IDA criteria were selected such that the dependent scan was always carried out on the two most intense ions, which exceeded 500 counts/s.

\section{HR-MS and HR-MS/MS analyses.}

Accurate mass measurements and high-resolution collisioninduced dissociations were performed offline, after fraction collection, on a quadrupole-time of flight instrument (QSTAR pulsar $i$; Sciex) using the electrospray in positive mode ionization. Collected experimental fractions and commercial standards typically were infused at 5 to $10 \mu \mathrm{l} / \mathrm{min}$ using a built-in syringe pump. Parameters of the source used the following settings: nitrogen as curtain and nebulizer gas; curtain gas at 33 psi and GS1 at $30 \mathrm{psi}$; and capillary voltage of $5.2 \mathrm{kV}$. Declustering potential and collision energy was optimized for each of the analyzed compounds. The instrument that was controlled with Analyst QS 1.1. software was optimized in such a way as to minimize dissociations induced by upfront collisions, with a resolving power of approximately 8,000. Data were processed with PeakView (ver. 1.2; Sciex).

\section{Measuring essential element contents in nodules.}

To obtain concentrations of essential elements, dried nodules were first ground using a mortar and pestle. Then, $0.2 \mathrm{~g}$ of the resulting fine powder was burnt at $500^{\circ} \mathrm{C}$ and dissolved in $25 \mathrm{ml}$ of deionized hot water in the presence of $0.25 \mathrm{M} \mathrm{HCl}$. For each of the plant-rhizobia combinations, three such independent nodule preparations were made. Concentrations of $\mathrm{K}$ and $\mathrm{Ca}$ were determined by flame photometry. $\mathrm{P}$ concentration was determined by spectrophotometric measurements using the ammonium vanadate molybdate method (Agricultural Development and Advisory Service 1986). Total Mg, Fe, Cu, Zn, Mo, $\mathrm{Co}$, and $\mathrm{Mn}$ contents were determined by atomic absorption spectrophotometry (AAS SHIMADZU AA-6300; Shimadzu Scientific Instruments, Columbia, MA, U.S.A.) using the flame (for $\mathrm{Mg}, \mathrm{Fe}, \mathrm{Cu}$, and $\mathrm{Zn}$ ) or graphite furnace (for $\mathrm{Mo}, \mathrm{Co}$, and $\mathrm{Mn})$ techniques. Each value reported in Table 3 is the mean of three independent measurements.

\section{ACKNOWLEDGMENTS}

We thank N. Giot and A. Muninovic for their help in many aspects of this work.

\section{LITERATURE CITED}

Allen, O. N., and Allen, E. K. 1936. Root nodule bacteria of some tropical leguminous plants. I. Cross-inoculation studies with Vigna sinensis L. Soil Sci. 42:61-77.

Broughton, W. J., and Dilworth, M. J. 1971. Control of leghaemoglobin synthesis in snake beans. Biochem. J. 125:1075-1080.

Broughton, W. J., Wong, C.-H., Lewin, A., Samrey, U., Myint, H., Meyer, H., Dowling, D. N., and Simon, R. 1986. Identification of Rhizobium plasmid sequences involved in recognition of Psophocarpus, Vigna, and other legumes. J. Cell Biol. 102:1173-1182.

Brzezowski, P., Richter, A. S., and Grimm, B. 2015. Regulation and function of tetrapyrrole biosynthesis in plants and algae. Biochim. Biophys. Acta 1847:968-985.

Bu, W., Myers, N., McCarty, J. D., O’Neill, T., Hollar, S., Stetson, P. L., and Sved, D. W. 2003. Simultaneous determination of six urinary porphyrins using liquid chromatography-tandem mass spectrometry. J. Chromatogr. B Analyt. Technol. Biomed. Life Sci. 783:411-423.

Caradus, J. R., and Silvester, W. B. 1979. Rhizobium specific anthocyaninlike marker in lupin nodules. Plant Soil 51:437-440.

Cloonan, M. J. 1963. Black nodules on Dolichos. Aust. J. Sci. 26:121.

Dailey, H. A., Dailey, T. A., Gerdes, S., Jahn, D., Jahn, M., O’Brian, M. R., and Warren, M. J. 2017. Prokaryotic heme biosynthesis: Multiple pathways to a common essential product. Microbiol. Mol. Biol. Rev. 81: e00048-16.

Danton, M., and Lim, C. K. 2006. Porphyrin profiles in blood, urine and faeces by HPLC/electrospray ionization tandem mass spectrometry. Biomed. Chromatogr. 20:612-621.

Downie, J. A. 2014. Legume nodulation. Curr. Biol. 24:R184-R190.

Eaglesham, A. R., Ahmad, M. H., Hassouna, S., and Goldman, B. J. 1982. Cowpea rhizobia producing dark nodules: Use in competition studies. Appl. Environ. Microbiol. 44:611-618.

Freiberg, C., Fellay, R., Bairoch, A., Broughton, W. J., Rosenthal, A., and Perret, X. 1997. Molecular basis of symbiosis between Rhizobium and legumes. Nature 387:394-401.

Fumeaux, C., Bakkou, N., Kopćinska, J., Golinowski, W., Westenberg, D. J., Müller, P., and Perret, X. 2011. Functional analysis of the nifQdctA1y4vGHIJ operon of Sinorhizobium fredii strain NGR234 using a transposon with a NifA-dependent read-out promoter. Microbiology 157:2745-2758.

González-Guerrero, M., Escudero, V., Saéz, Á., and Tejada-Jiménez, M. 2016. Transition metal transport in plants and associated endosymbionts: Arbuscular mycorrhizal fungi and rhizobia. Front. Plant Sci. 7:1088.

González-Guerrero, M., Matthiadis, A., Sáez, Á., and Long, T. A. 2014. Fixating on metals: New insights into the role of metals in nodulation and symbiotic nitrogen fixation. Front. Plant Sci. 5:45.

Günther, C., Schlereth, A., Udvardi, M., and Ott, T. 2007. Metabolism of reactive oxygen species is attenuated in leghemoglobin-deficient nodules of Lotus japonicus. Mol. Plant-Microbe Interact. 20:1596-1603.

Hakoyama, T., Niimi, K., Watanabe, H., Tabata, R., Matsubara, J., Sato, S., Nakamura, Y., Tabata, S., Jichun, L., Matsumoto, T., Tatsumi, K., Nomura, M., Tajima, S., Ishizaka, M., Yano, K., Imaizumi-Anraku, H., Kawaguchi, M., Kouchi, H., and Suganuma, N. 2009. Host plant genome overcomes the lack of a bacterial gene for symbiotic nitrogen fixation. Nature 462:514-517.

Hernandez, J. A., Curatti, L., Aznar, C. P., Perova, Z., Britt, R. D., and Rubio, L. M. 2008. Metal trafficking for nitrogen fixation: NifQ donates 
molybdenum to NifEN/NifH for the biosynthesis of the nitrogenase FeMo-cofactor. Proc. Natl. Acad. Sci. U.S.A. 105:11679-11684.

Hernandez, J. A., George, S. J., and Rubio, L. M. 2009. Molybdenum trafficking for nitrogen fixation. Biochemistry 48:9711-9721.

Hu, Y., and Ribbe, M. W. 2016. Biosynthesis of the Metalloclusters of Nitrogenases. Annu. Rev. Biochem. 85:455-483.

Imperial, J., Ugalde, R. A., Shah, V. K., and Brill, W. J. 1984. Role of the nifQ gene product in the incorporation of molybdenum into nitrogenase in Klebsiella pneumoniae. J. Bacteriol. 158:187-194.

Jiménez-Vicente, E., Hernandez, J. A., Echavarri-Erasum, C., and Rubio, L. M. 2015. Biosynthesis of the iron-molybdenum cofactor of nitrogenase. Pages 75-86 in: Biological Nitrogen Fixation. F. J. de Bruijn, ed. John Wiley \& Sons, Inc., Hoboken, NJ, U.S.A.

Keilin, D. 1925. On cytochrome, a respiratory pigment, common to animals, yeast, and higher plants. P. R. Soc. Lond. B 98:312-339.

Koch, M., Delmotte, N., Rehrauer, H., Vorholt, J. A., Pessi, G., and Hennecke, H. 2010. Rhizobial adaptation to hosts, a new facet in the legume root-nodule symbiosis. Mol. Plant-Microbe Interact. 23:784-790.

Larkin, R. M. 2016. Tetrapyrrole signaling in plants. Front. Plant Sci. 7:1586.

Lee, M. J., Chun, S. J., Kim, H. J., Kwon, A. S., Jun, S. Y., Kang, S. H., and Kim, P. 2012. Porphyrin derivatives from a recombinant Escherichia coli grown on chemically defined medium. J. Microbiol. Biotechnol. 22:1653-1658.

Lewin, A., Cervantes, E., Chee-Hoong, W., and Broughton, W. J. 1990. nod $S$, two new nod genes of the broad host range Rhizobium strain NGR234 encode host-specific nodulation of the tropical tree Leucaena leucocephala. Mol. Plant-Microbe Interact. 3:317-326.

Lim, C. K., Danton, M., Clothier, B., and Smith, A. G. 2006. Dihydroxy-, hydroxyspirolactone-, and dihydroxyspirolactone-urochlorins induced by 2,3,7,8-tetrachlorodibenzo-p-dioxin in the liver of mice. Chem. Res. Toxicol. 19:1660-1667.

Maskall, S. M., Dart, P., and Carpenter, J. 1972. Black nodule pigments. Rep. Rothamsted Exp. Stn. 1971:98-99.

Masson-Boivin, C., Giraud, E., Perret, X., and Batut, J. 2009. Establishing nitrogen-fixing symbiosis with legumes: How many rhizobium recipes? Trends Microbiol. 17:458-466.

Agricultural Development and Advisory Service. 1986. The Analysis of Agricultural Materials: A Manual of the Analytical Methods used by the Agricultural Development and Advisory Service/Ministry of Agriculture, Fisheries and Food. H.M.S.O., London.

Mochizuki, N., Tanaka, R., Grimm, B., Masuda, T., Moulin, M., Smith, A. G., Tanaka, A., and Terry, M. J. 2010. The cell biology of tetrapyrroles: A life and death struggle. Trends Plant Sci. 15:488-498.

Nouwen, N., Arrighi, J. F., Cartieaux, F., Chaintreuil, C., Gully, D., Klopp, C., and Giraud, E. 2017. The role of rhizobial (NifV) and plant (FEN1) homocitrate synthases in Aeschynomene/photosynthetic Bradyrhizobium symbiosis. Sci. Rep. 7: Article 448.
Österman, J., Mousavi, S. A., Koskinen, P., Paulin, L., and Lindström, K. 2015. Genomic features separating ten strains of Neorhizobium galegae with different symbiotic phenotypes. BMC Genomics 16:348.

Ott, T., Sullivan, J., James, E. K., Flemetakis, E., Günther, C., Gibon, Y., Ronson, C., and Udvardi, M. 2009. Absence of symbiotic leghemoglobins alters bacteroid and plant cell differentiation during development of Lotus japonicus root nodules. Mol. Plant-Microbe Interact. 22:800-808.

Ott, T., van Dongen, J. T., Günther, C., Krusell, L., Desbrosses, G., Vigeolas, H., Bock, V., Czechowski, T., Geigenberger, P., and Udvardi, M. K. 2005. Symbiotic leghemoglobins are crucial for nitrogen fixation in legume root nodules but not for general plant growth and development. Curr. Biol. 15:531-535.

Poole, P., Ramachandran, V., and Terpolilli, J. 2018. Rhizobia: From saprophytes to endosymbionts. Nat. Rev. Microbiol. 16:291-303.

Reedy, C. J., and Gibney, B. R. 2004. Heme protein assemblies. Chem. Rev. 104:617-650.

Rimington, C. 1960. Spectral-absorption coefficients of some porphyrins in the Soret-band region. Biochem. J. 75:620-623.

Rubio, L. M., and Ludden, P. W. 2005. Maturation of nitrogenase: A biochemical puzzle. J. Bacteriol. 187:405-414.

Rubio, L. M., and Ludden, P. W. 2008. Biosynthesis of the ironmolybdenum cofactor of nitrogenase. Annu. Rev. Microbiol. 62:93-111.

Sprent, J. I., Ardley, J., and James, E. K. 2017. Biogeography of nodulated legumes and their nitrogen-fixing symbionts. New Phytol. 215:40-56.

Stamford, N. P., and Neptune, M. L. 1978. Host specificity and strain competition in the Rhizobium-Vigna sinensis (L.) Endl. symbiosis. Pages 337-338 in: Limitations and Potentials for Biological Nitrogen Fixation in the Tropics. J. Dobereiner, R. H. Burris, and A. Hollaender, eds. Plenum Publishing Corp., New York.

Stanley, J., Dowling, D. N., and Broughton, W. J. 1988. Cloning of hemA from Rhizobium sp. NGR234 and symbiotic phenotype of a genedirected mutant in diverse legume genera. Mol. Gen. Genet. 215:32-37.

Uddin, M. R., Mclaughlin, W., and Ahmad, M. H. 1984. Competition between inoculum and native rhizobia for nodulation of cowpea (Vigna unguiculata (L) Walp): Use of a dark-nodule strain. Plant Soil 81:305-307.

Udvardi, M., and Poole, P. S. 2013. Transport and metabolism in legumerhizobia symbioses. Annu. Rev. Plant Biol. 64:781-805.

Van den Eede, G., Deblaere, R., Goethals, K., Van Montagu, M., and Holsters, M. 1992. Broad host range and promoter selection vectors for bacteria that interact with plants. Mol. Plant-Microbe Interact. 5:228-234.

Zappa, S., Li, K., and Bauer, C. E. 2010. The tetrapyrrole biosynthetic pathway and its regulation in Rhodobacter capsulatus. Adv. Exp. Med. Biol. 675:229-250.

Zheng, L., White, R. H., and Dean, D. R. 1997. Purification of the Azotobacter vinelandii nifV-encoded homocitrate synthase. J. Bacteriol. 179:5963-5966. 